\title{
Reply to Kersting et al. Comment on "Wunsch et al. The Impact of COVID-19 on the Interrelation of Physical Activity, Screen Time and Health-Related Quality of Life in Children and Adolescents in Germany: Results of the Motorik-Modul Study. Children 2021, 8, 98"
}

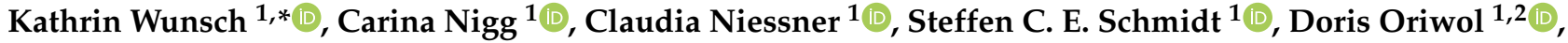 \\ Anke Hanssen-Doose $^{2} \mathbb{D}$, Alexander Burchartz ${ }^{1} \mathbb{D}$, Ana Eichsteller ${ }^{1}$, Simon Kolb ${ }^{1} \mathbb{D}$, Annette Worth ${ }^{2}$ \\ and Alexander Woll ${ }^{1}$
}

1 Institute of Sports and Sports Science, Karlsruhe Institute of Technology, 76131 Karlsruhe, Germany; carina.nigg@partner.kit.edu (C.N.); claudia.niessner@kit.edu (C.N.); Steffen.schmidt@kit.edu (S.C.E.S.);

check for

updates

Citation: Wunsch, K.; Nigg, C.; Niessner, C.; Schmidt, S.C.E.; Oriwol,

D.; Hanssen-Doose, A.; Burchartz, A.;

Eichsteller, A.; Kolb, S.; Worth, A.; et al. Reply to Kersting et al. Comment on "Wunsch et al. The Impact of COVID-19 on the Interrelation of Physical Activity, Screen Time and Health-Related Quality of Life in Children and Adolescents in Germany: Results of the Motorik-Modul Study. Children 2021, 8, 98". Children 2021, 8, 533. https://doi.org/10.3390/ children 8070533

Academic Editor: Zoe Knowles

Received: 19 May 2021

Accepted: 16 June 2021

Published: 23 June 2021

Publisher's Note: MDPI stays neutral with regard to jurisdictional claims in published maps and institutional affiliations.

Copyright: (c) 2021 by the authors. Licensee MDPI, Basel, Switzerland. This article is an open access article distributed under the terms and conditions of the Creative Commons Attribution (CC BY) license (https:// creativecommons.org/licenses/by/ $4.0 /)$ doris.oriwol@partner.kit.edu (D.O.); alexander.burchartz@kit.edu (A.B.); ana.eichsteller@kit.edu (A.E.); simon.kolb@kit.edu (S.K.); alexander.woll@kit.edu (A.W.)

2 Institute of Movement and Sport, University of Education Karlsruhe, 76133 Karlsruhe, Germany; anke.hanssen-doose@ph-karlsruhe.de (A.H.-D.); annette.worth@ph-karlsruhe.de (A.W.)

* Correspondence: Kathrin.wunsch@kit.edu; Tel.: +49-721-608-45-431

In reply to the comment of Kersting et al. [1], there is a need to mention that there are multiple health behaviors, which may relate to health-related quality of life. Nudelman and Shiloh attempted to cluster these behaviors and created a taxonomy consisting of 66 health behaviors [2]. In a network analytic approach, they screened all those behaviors for interrelatedness and centrality [3] and found eating behavior to be one of the most central ones. This, in turn, may substantiate the assumption determined by the authors of the respective comment that dietary behavior may be as important in the prediction of HRQoL as physical activity and screen time. A recent review and meta-analysis of Wu and colleagues [4] support this assumption, as the authors found that dietary behavior was indeed associated with health-related quality of life in children and adolescents.

However, next to nutrition, Nudelman and Shiloh [2] identified three other relevant domains of health behaviors: general well-being, risk avoidance, and health maintenance. Our current examination focused on the latter domain, which includes physical (in-) activity and exercise. Considering those four domains, we agree that nutrition might be an important factor when investigating relationships between health behaviors and health-related quality of life. For a comprehensive investigation, we would like to add that health behaviors of the remaining two categories, risk avoidance (e.g., substance use) and general well-being including stress (e.g., stress, relationships), should also be added.

Furthermore, we recommend that the directionality of the associations still needs to be investigated. Contrary to our hypothesis, we did not find physical activity to be a significant predictor of health-related quality of life during the COVID-19 pandemic. Considering the nutrition domain, there is only a limited number of studies that investigated longitudinal associations between dietary behaviors and health-related quality of life in children and adolescents [4], warranting future research to investigate if a positive longitudinal relationship exists across the developmental period of childhood and adolescence. In the context of the COVID-19 pandemic, only a few cross-sectional investigations exist, examining changes in nutrition behavior in the pediatric population [5], while we are not aware of any studies that investigated associations between nutrition and health-related quality of life.

In conclusion, we would recommend investigating associations between health behaviors and health-related quality of life beyond physical activity and screen time, including 
nutrition and dietary behaviors, in addition to health behaviors concerning general wellbeing and risk avoidance.

Author Contributions: Writing—original draft preparation, K.W.; writing—review and editing, K.W., C.N. (Carina Nigg), C.N. (Claudia Niessner), S.C.E.S., D.O., A.H.-D., A.B., A.E., S.K., A.W. (Annette Worth), A.W. (Alexander Woll); funding acquisition, A.W. (Annette Worth), A.W. (Alexander Woll). All authors have read and agreed to the published version of the manuscript.

Funding: This work was supported by the Federal Ministry of Education and Research [01ER1503] within the research program 'long-term studies' in public health research. It has been developed within the Motorik-Modul Longitudinal Study (MoMo) (2009-2021): Physical fitness and physical activity as determinants of health development in children and adolescents. The funding source played no role in study design, data collection, analysis, and interpretation, but agreed to the submission of this manuscript.

Institutional Review Board Statement: The study was conducted according to the guidelines of the Declaration of Helsinki, and approved by the Ethics Committee of the Karlsruhe Institute of Technology.

Informed Consent Statement: Informed consent was obtained from all subjects involved in the study.

Data Availability Statement: Not appplicable.

Conflicts of Interest: The authors declare no conflict of interest.

\section{References}

1. Kersting, M.; Kalhoff, H.; Lücke, T. Comment on Wunsch et al. The Impact of COVID-19 on the Interrelation of Physical Activity, Screen Time and Health-Related Quality of Life in Children and Adolescents in Germany: Results of the Motorik-Modul Study. Children 2021, 8, 98. Children 2021, 8, 520. [CrossRef]

2. Nudelman, G.; Shiloh, S. Mapping health behaviors: Constructing and validating a common-sense taxonomy of health behaviors. Soc. Sci. Med. 2015, 146, 1-10. [CrossRef] [PubMed]

3. Nudelman, G.; Kalish, Y.; Shiloh, S. The centrality of health behaviours: A network analytic approach. Br. J. Health Psychol. 2018, 24, 215-236. [CrossRef] [PubMed]

4. Wu, X.Y.; Zhuang, L.H.; Li, W.; Guo, H.W.; Zhang, J.H.; Zhao, Y.K.; Hu, J.W.; Gao, Q.Q.; Luo, S.; Ohinmaa, A.; et al. The influence of diet quality and dietary behavior on health-related quality of life in the general population of children and adolescents: A systematic review and meta-analysis. Qual. Life Res. 2019, 28, 1989-2015. [CrossRef] [PubMed]

5. Zemrani, B.; Gehri, M.; Masserey, E.; Knob, C.; Pellaton, R. A hidden side of the COVID-19 pandemic in children: The double burden of undernutrition and overnutrition. Int. J. Equity Health 2021, 20, 44. [CrossRef] [PubMed] 